\title{
Potential utility of xenobiotic mitogens in the context of liver regeneration in the elderly and living-related transplantation
}

\author{
Amedeo Columbano ${ }^{1}$, Michela Simbula ${ }^{1}$, Monica Pibiri ${ }^{1}$, Andrea Perra ${ }^{1}$, Adolfo Pisanu ${ }^{2}$, Alessandro Uccheddu ${ }^{2}$ \\ and Giovanna M Ledda-Columbano'
}

Although liver regeneration occurring after partial hepatectomy $(\mathrm{PH})$ is greatly reduced in aged mice, liver hyperplasia induced by xenobiotic mitogens was found to be age independent. Here, we investigated the potential utility of mitogens in stimulating liver regeneration in old mice subjected to two-third PH. Although virtually no hepatocytes entered $\mathrm{S}$ phase $48 \mathrm{~h}$ after $\mathrm{PH}$, pretreatment ( $2 \mathrm{~h}$ prior to surgery) with 1,4-bis(2-(3,5-dichloropyridyloxy)benzene (TCPOBOP), a ligand of constitutive androstane receptor, induced an increase of bromodeoxyuridine incorporation and enhanced the expression of cyclin D1, cyclin A and proliferating cell nuclear antigen. Next, we investigated the potential utility of mitogens in the context of donor conditioning prior to living-related transplantation. Three days after TCPOBOP administration to intact young mice, an almost doubling of the liver mass and DNA content occurred; the regenerative response to two-third resection of the TCPOBOP-induced hyperplastic liver was similar to that of mice subjected to $\mathrm{PH}$ alone, suggesting that an increased liver mass at the time of surgery does not inhibit the regenerative capacity. The present results suggest that mitogen-induced hyperplasia is a promising tool in conditions characterized by reduced regenerative capacity, such as in the elderly, or when a rapid increase of liver mass is required, such as in living-related transplantation.

Laboratory Investigation (2008) 88, 408-415; doi:10.1038/labinvest.2008.3; published online 11 February 2008

KEYWORDS: TCPOBOP; partial hepatectomy; liver regeneration; aging; cyclins

Life expectancy has increased over the past century from 48 years in 1900 to 77 years in 2001. ${ }^{1}$ Thus, because of the increase in the number of elderly patients with liver disease, many of these patients may be considered for surgery, and, in addition, because of the shortage of available organs for transplantation, older donors may also become a major source of liver grafts. Unfortunately, aging is associated with a decline in the intrinsic metabolic activity of the hepatic parenchyma and in the expression of genes coding for proteins involved in metabolism, mitochondrial respiration and xenobiotic biotransformation. ${ }^{2}$

The impact of age of a cadaveric or living donor on the outcome of liver transplantation and the results of liver resection in the elderly patients have been evaluated in only a few clinical studies and are subject to considerable discussion. Although one study failed to show any significant difference, ${ }^{3}$ others have suggested an increased risk for primary non-function in liver transplant recipients receiving a graft from older donors. ${ }^{4-6}$ In this context, it is of interest to note that a major characteristic of the aging process is a decline in the cellular capacity to respond to proliferative stimuli. Indeed, several studies on the regenerative response that follows two-third partial hepatectomy $(\mathrm{PH})$ have shown that the response to $\mathrm{PH}$ was both delayed and reduced with aging in rats and mice. ${ }^{7,8}$ Although the mechanism(s) responsible for the agerelated decline in the post-hepatectomy proliferative response are not known, an age-related switch from cyclin-dependent kinase inhibition to repression of E2F transcription ${ }^{9}$ and/or a decrease in expression of a gene coding for a critical Forkhead Box transcription factor have been correlated with reduced proliferation of regenerating hepatocytes from old rodents. ${ }^{10}$ In recent years, an increasing number of agents capable of inducing hepatomegaly without causing liver injury (direct hyperplasia) have been identified. ${ }^{11}$ Most of these agents are

\footnotetext{
${ }^{1}$ Dipartimento di Tossicologia, Sezione di Oncologia e Patologia Molecolare, Cagliari, Italy and ${ }^{2}$ Clinica Chirurgica, Università di Cagliari, Cagliari, Italy Correspondence: Dr A Columbano, PhD, Dipartimento di Tossicologia, Sezione di Oncologia e Patologia Molecolare, Via Porcell 4, Cagliari 09124, Italy. E-mail: columbano@unica.it
}

Received 19 November 2007; revised 20 December 2007; accepted 23 December 2007 
ligands of the superfamily of steroid/thyroid hormone nuclear receptors. ${ }^{11}$ Activated nuclear receptors not only regulate genes involved in lipid metabolism, adipogenesis, xenobiotic detoxification and differentiation ${ }^{12}$ but also stimulate hepatocyte proliferation. ${ }^{13}$ Interestingly, early changes considered to be essential for liver regeneration after $\mathrm{PH}:{ }^{14-16}$ activation of the transcription factors activating protein-1 (AP-1), nuclear factor- $\kappa \mathrm{B}$, signal transducer activator of transcription 3 and C/enhancer-binding protein; increased expression of immediate early genes such as c-fos, c-jun, $c-m y c$, liver regenerating factor- 1 , and early growth response- 1 and release of the cytokines tumor-necrosis factor- $\alpha$ and interleukin- 6 are not observed in nuclear receptor-mediated hepatocyte proliferation. ${ }^{17,18}$ The early signal transduction pathways involved in nuclear receptor-mediated hepatocyte proliferation are, therefore, different from those involved in liver regeneration. Notably, it was shown that hepatocyte proliferation induced by ТСРОВOP, a ligand of the constitutive androstane receptor (CAR), is age independent, suggesting that hepatocytes retain their proliferative capacity in old age despite impaired liver regeneration. ${ }^{19}$

On the basis of these observations, the first aim of this study was to investigate whether pretreatment with xenobiotic mitogens, for example ТСРОВОР, may allow the growth of the liver in conditions associated with a reduced regenerative capacity, such as the elderly. In particular, we address the question whether nuclear receptor-mediated signal transduction pathways could be capable of bypassing the growth-constrained environment of an aged liver, thus improving its proliferative capacity after $70 \% \mathrm{PH}$.

Another condition where the capacity of xenobiotic mitogens could be applied to human therapy is living-related transplantation. Indeed, the ratio of liver to body mass has emerged as a critical parameter in assessing the feasibility of living-related liver transplants, thus ensuring availability of an appropriate mass of liver to provide immediate function in the recipient, while maintaining the appropriate mass and function in the donor; a graft/recipient body weight ratio of $0.8-1.0 \%$ has been suggested as a guideline. ${ }^{20}$ Given the relative scarcity of potential donors for livingrelated transplantation, it follows that if the number of recipients is large, the requirement to find a donor who can safely provide adequate liver mass may further limit donor selection.

Until recently, relatively little attention has been paid to factors and techniques that could increase the size of a donor liver before transplantation. ${ }^{21}$ Clearly, such approaches are required to be safe and applicable in man, but developing such approaches requires in vivo investigation in animal models.

Therefore, the second aim of this study was to investigate whether following $70 \% \mathrm{PH}$, a mitogen-induced hyperplastic liver could still undergo an efficient regenerative process or, on the contrary, hepatomegaly exerts a negative effect on the subsequent post-operative regeneration.

\section{MATERIALS AND METHODS \\ Animals}

Female CD-1 mice (10 weeks and 18 months old), purchased from Charles River (Milano, Italy), were used. Procedures were performed in accordance with the Guidelines for the Care and Use of Laboratory Animals of the animal ethics committee of this University. Hepatocyte proliferation was induced by gavage treatment with TCPOBOP (a gift from $\mathrm{Dr}$ BA Diwan, Frederick Cancer Center, MD, USA), at a dose of 1 or $3 \mathrm{mg} / \mathrm{kg}$ body weight, dissolved in dimethylsulfoxidecorn oil solution. The lower dose of ТСРОВОР was used in mice subjected to $\mathrm{PH}$ shortly after treatment to allow metabolic handling of the chemical by the residual liver. Controls received an equivalent amount of the vehicle. $\mathrm{PH}$ was performed according to Higgins and Anderson. ${ }^{22}$ Five to seven mice per group were used in animal experiments.

\section{Experimental Protocol 1}

Eighteen months old mice were given TCPOBOP at a dose of $1 \mathrm{mg} / \mathrm{kg}$ body weight. Two hours later, TCPOBOP-treated mice and controls were subjected to $70 \% \mathrm{PH}$, and the animals were killed $48 \mathrm{~h}$ later, a time representing the peak of mouse liver regeneration. Five mice treated with TСРОВОР were killed at the same time point, but in the absence of $\mathrm{PH}$. For determination of total hepatocyte proliferation, bromodeoxyuridine (BrdU, Sigma Chem. Co., St Louis, MO, USA) was given in drinking water $(1 \mathrm{mg} / \mathrm{ml})$, starting $4 \mathrm{~h}$ after surgery.

\section{Experimental Protocol 2}

Ten weeks old mice received a single injection of TСРОВOP $(3 \mathrm{mg} / \mathrm{kg}$ body weight) or an equivalent amount of the vehicle. Three days later, half of the mice from each group were killed, whereas the remaining mice were subjected to $70 \% \mathrm{PH}$ and killed $72 \mathrm{~h}$ after surgery. BrdU was given in drinking water $(1 \mathrm{mg} / \mathrm{ml})$.

\section{Histology and Immunohistochemistry}

Liver sections were fixed in $10 \%$ buffered formalin and processed for staining with hematoxylin and eosin or immunohistochemistry. The remaining liver was snap-frozen in liquid nitrogen and kept at $-80^{\circ} \mathrm{C}$ until use. Mouse monoclonal anti-BrdU antibody was obtained from Becton Dickinson (San Jose, CA, USA), and the peroxidase method was used to stain BrdU-positive hepatocytes. Peroxidase-conjugated goat anti-mouse immunoglobulin was obtained from Dako (Dako EnVision ${ }^{+ \text {тм }}$ Peroxidase Mouse, Dako Corporation, Carpinteria, CA, USA). The sites of peroxidase binding were detected by $3,3^{\prime}$-diaminobenzidine. A segment of duodenum, an organ with a high rate of cell proliferation, was included from each mouse to confirm delivery of the DNA precursor. The labelling index (LI) was expressed as the number of BrdU-positive nuclei/ 100 hepatocyte nuclei. Results are expressed as means \pm s.e. of $4-5$ mice per group. At least 2000 hepatocyte nuclei per liver were scored. Mitotic 
activity was expressed as the number of mitoses/1000 hepatocytes. Results are expressed as means \pm s.e. of $4-5$ rats per group. At least 5000 hepatocyte nuclei per liver were scored.

\section{DNA Content}

Total hepatic DNA content was determined by the diphenylamine method as described previously. ${ }^{23}$

\section{Liver Function}

Prothrombin time (PT) was determined in the blood using a Thrombotest (Thrombotest, ISI 1.01, Axis-Shield PoC AS, Oslo, Norway), according to the manufacturer's instruction. Albumin content was determined in the plasma using a photometric color test (Albumin OSR6x02, Olympus, Dublin, Ireland).

\section{Northern Blot}

Isolation of total RNA, electrophoretic separation, transfer to Hybond $\mathrm{N}$ membrane, labelling, hybridization and washing of membranes were performed as described previously. ${ }^{19,24}$ The probe for $\beta$-actin was prepared from total RNA using SuperScript $^{\mathrm{TM}}$ IIIOne-Step RT-PCR System with Platinum Taq DNA Polymerase (Invitrogen, Carlsbad, CA, USA). Following PCR primers were used for $\beta$-actin: forward AGC CATGTACGTAGCCATCC and reverse AAGGGTGTAAAAC GCAGCTC. Probes for Cyclin D1 and Cyp2b10 were prepared from total RNA, reverse-transcribed with ThermoScript RT-PCR System (Invitrogen) and PCR amplified with Platinum Taq DNA Polymerase (Invitrogen) using the following primers: for Cyclin D1 probe, forward CCCAGACCCTCACACTCAGA and reverse ATCCACTCAGGC ATCGACAT; for Cyp2b10 probe, forward AAATATGGAGA TGTGTTCACAGTGCACC and reverse TGTAGAGCTGAAC TCAGGATGGGGTA.

\section{Western Blot Analysis}

Preparation of nuclear extracts and western blot analysis were performed as described previously. ${ }^{19}$ The following antibodies were used: mouse monoclonal antibodies against cyclin D1 (72-13G) and proliferating cell nuclear antigen (PCNA) (PC-10), rabbit polyclonal antibodies against cyclin A (C-19) and goat polyclonal antibodies against p107 (C-18) (Santa Cruz Biotechnology, Santa Cruz, CA, USA); mouse monoclonal antibodies against p27 (Kip1-p27, Transduction Laboratories, Lexington, KY, USA) and albumin (Bethyl Laboratories, Montgomery, TX, USA). Primary antibodies were visualized using anti-mouse or anti-rabbit or anti-goat horseradish peroxidase-conjugated IgG (Santa Cruz Biotechnology). Immunoreactive bands were identified with chemiluminescence detection system (Supersignal Substrate; Pierce, Rockford, IL, USA).

\section{Statistical Analysis}

Comparison between the two groups was performed by Student's $t$-test.

\section{RESULTS}

\section{Experiment 1}

First, we sought to find whether TCPOBOP-induced CAR activation shortly prior to $70 \% \mathrm{PH}$ could stimulate hepatocyte proliferation, thus restoring an appropriate regenerative response in old mice. To allow metabolic handling of this chemical by the residual liver after $\mathrm{PH}$, a dose $1 \mathrm{mg} / \mathrm{kg}$ of TCPOBOP, three times lower than that commonly used, was administered. TCPOBOP causes immediate upregulation of Cyp2b10 in young mice; ${ }^{25}$ accordingly, we evaluated whether the response to ТСРОВOP was still present in aged animals. Two hours after treatment with TСРОВOP, a strong increase in the hepatic mRNA levels of Cyp2b10, a CAR-target gene, was observed (Figure 1), suggesting that transcriptional activity of CAR was maintained in aged mouse liver. At this time point, mice were subjected to two-third $\mathrm{PH}$ and were killed $48 \mathrm{~h}$ after $\mathrm{PH}$; two other groups of mice were either subjected to surgery, without TCPOBOP, or treated with TCPOBOP, without any surgery. No mortality was observed in $\mathrm{PH}$ or TCPOBOP $+\mathrm{PH}$ mice. In agreement with the literature, ${ }^{8,10}$ liver regeneration was severely impaired in old mice subjected to $70 \% \mathrm{PH}$ (Figure 2); indeed, $48 \mathrm{~h}$ after surgery, virtually no hepatocyte nuclei were BrdU-positive; on the other hand, treatment with TСРОВOP $2 \mathrm{~h}$ prior to $\mathrm{PH}$ induced a very efficient proliferative response (Figure 2a); LI was $21.3 \% \pm 5.4$ in TCРОВOP $+\mathrm{PH}$ mice $v s 1 \% \pm 0.2$ of mice subjected to $\mathrm{PH}$ alone (Figure $2 \mathrm{~b}$ ). The entry into $\mathrm{S}$ phase observed in the liver of TCPOBOP $+\mathrm{PH}$ was accompanied by a fourfold increase of mitoses (Figure 2c). Notably, the proliferative response observed in TСРОBOP-pretreated mice appears to be entirely due to the mitogenic activity of the xenobiotic; indeed, administration of ТСРОВOP to intact mice resulted in an LI of $20.8 \% \pm 3.2$, which was similar to the LI observed in TCPOBOP $+\mathrm{PH}$ mice $(21.3 \% \pm 5.4)$.

The increased hepatocyte entry into cell cycle observed in the liver of mice receiving ТСРОВOP prior to $\mathrm{PH}$ was associated with enhanced levels of cyclin D1 mRNA (Figure 3a) and protein (Figure $3 \mathrm{~b}$ ), compared with those of mice subjected to $\mathrm{PH}$ alone; together with its partners CDK4 and CDK6, cyclin D1 is thought to stimulate entry into S phase

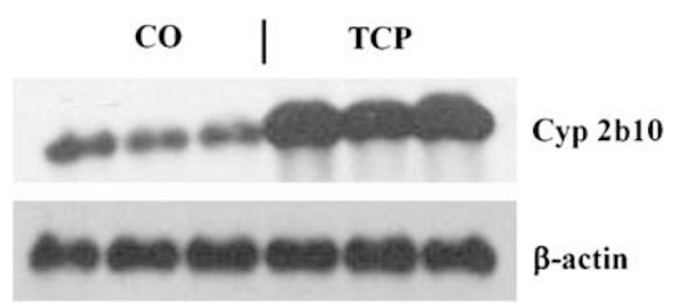

Figure 1 Induction of Cyp2b10 mRNA levels in the liver of aged mice treated with TCPOBOP. Total RNA was prepared from mouse liver $2 \mathrm{~h}$ after treatment with TCPOBOP $(1 \mathrm{mg} / \mathrm{kg})$ and subjected to northern blot analysis as described in Materials and Methods. Each lane represents an individual sample. TCP; TCPOBOP-treated mice; CO; controls. $\beta$-actin was used as a loading control. 
a
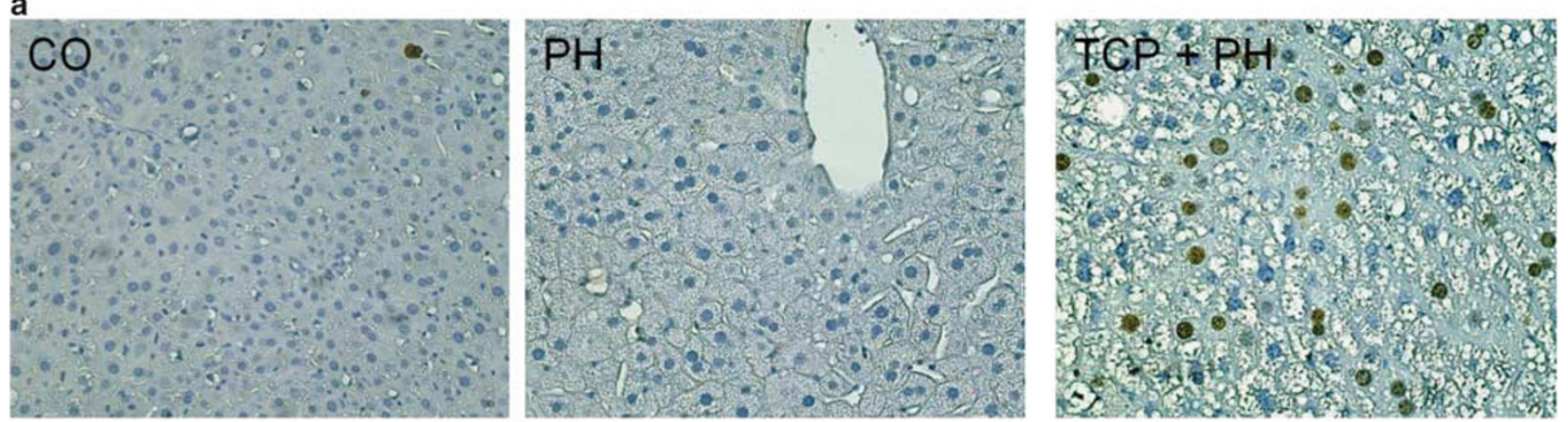

b

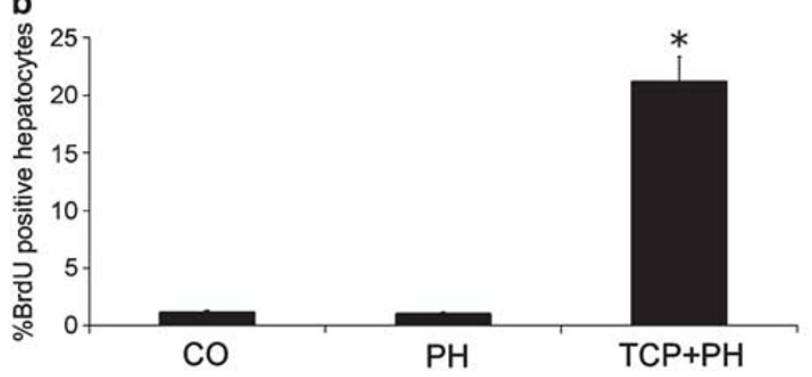

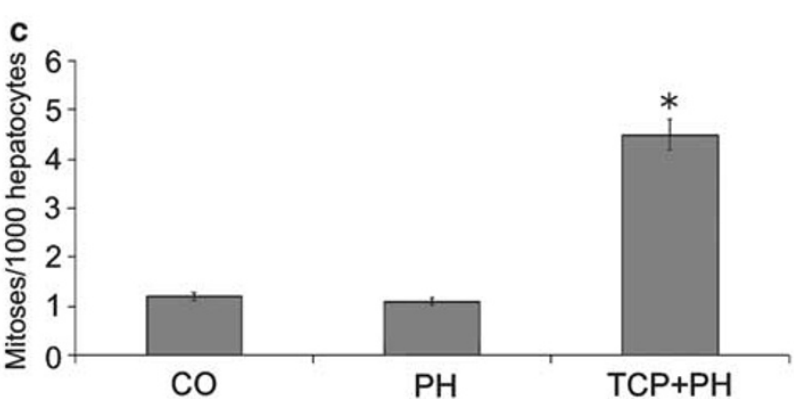

Figure 2 (a) Representative photomicrographs that illustrate the effect of pretreatment with TCPOBOP on hepatocyte proliferation in aged mice subjected to $\mathrm{PH}$. Mice were subjected to $70 \% \mathrm{PH}$, with or without pretreatment, with a single dose of TCPOBOP $(1 \mathrm{mg} / \mathrm{kg})$ and killed $48 \mathrm{~h}$ later. All mice were given $\mathrm{BrdU}(1 \mathrm{mg} / \mathrm{ml})$ in drinking water until the time of killing ( $\times 200$, sections counterstained with hematoxylin). TCP, TCPOBOP-treated mice; CO, controls.

(b) Labelling index of hepatocytes from aged mice subjected to $70 \%$ PH with or without TCPOBOP pretreatment. At least 2000 hepatocyte nuclei per liver were scored. LI was expressed as number of BrdU-positive hepatocyte nuclei/100 nuclei. Results are expressed as means \pm s.e. of 5-6 mice per group. * Statistically significant from $\mathrm{PH}$ and controls for $P<0.001$. (c) Mitotic index was expressed as the number of hepatocytes entering mitosis/1000 hepatocytes. Results are expressed as means \pm s.e. of 5-6 mice per group. * Statistically significant from $\mathrm{PH}$ and controls for $P<0.001$.

by phosphorylating pRb family members, causing the release of E2F transcription factors, which then transcriptionally activates target genes. ${ }^{26}$ Pretreatment with TCPOBOP caused a strong enhancement of the nuclear levels of p107 compared with $\mathrm{PH}$ alone or unoperated mice (Figure $3 \mathrm{~b}$ ). The results also show that although the lack of liver regeneration observed in aged mice was associated with a strong increase in the hepatic levels of p27, pretreatment with TCPOBOP caused a significant reduction in the expression of this inhibitory protein.

Cyclin A and PCNA, two proteins associated to S phase, were also increased in the liver of mice treated with the mitogen prior to $\mathrm{PH}$. The increased proliferation observed in old mice, given the TCPOBOP, resulted in an increased liver weight/body weight ratio compared with mice subjected to $\mathrm{PH}$ alone (2.03 vs 1.63\%, $P<0.05$; Figure 3c).

\section{Experiment 2}

To investigate the potential utility of mitogen-induced hepatomegaly in the field of transplantation and resectional surgery, we evaluated the regenerative response of the liver in mice treated with a single dose of ТСРОВОР 3 days prior to performing $70 \% \mathrm{PH}$. As expected, administration of TCPOBOP to intact mice caused a strong increase in hepatocyte proliferation as shown by the enhanced nuclear incorporation of BrdU (50 vs 1.1\% of controls; Figure 4a), which was associated with an almost doubling of both the liver weight ( 2.85 vs $1.62 \mathrm{~g}$; Figure $4 \mathrm{~b})$ and the total DNA content (6.7 vs $3.8 \mathrm{mg}$; Figure 4c). At this time, to evaluate whether ТСРОВOP-induced hepatomegaly could interfere with liver regeneration, tow-third $\mathrm{PH}$ was performed in both controls and mitogen-treated mice, and the regenerative capacity of the liver was examined 3 days later, a time point when most of the hepatocyte replication had already taken place. No mortality was observed in both experimental groups. The results showed that the remnant liver mass $72 \mathrm{~h}$ after PH was much greater in mice who had received TCPOBOP than those who had received vehicle only (1.67 vs $1.0 \mathrm{~g}$; Table 1). That the increased liver mass observed in $\mathrm{PH}$ animals pretreated with ТСРОВОР was a true regenerative response and not simply a hypertrophic response is shown by the increased total DNA content ( $4.3 v s 2.4 \mathrm{mg})$ as well as by the analysis of the labelling index that was similar in both the groups (76.3 and $74.1 \%$ in TCPOBOP $+\mathrm{PH}$ and $\mathrm{PH}$ alone, respectively; Figure 5a). Analysis of cell-cycleassociated proteins revealed that the expression of cyclin D1, E2F and PCNA was essentially similar in the liver from $\mathrm{PH}$ and $\mathrm{TCPOBOP}+\mathrm{PH}$ mice (Figure $5 \mathrm{~b}$ ). These results demonstrate that the growth potential in response to surgery of the ТСРОВОР-induced hyperplastic liver was unchanged. Notably, the increased mass of the liver remnant was associated with increased liver function; indeed, two functional 
a

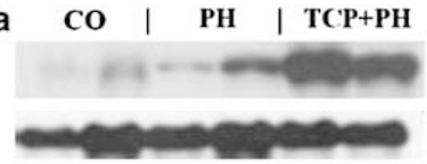

b co

PH | TCP+PH

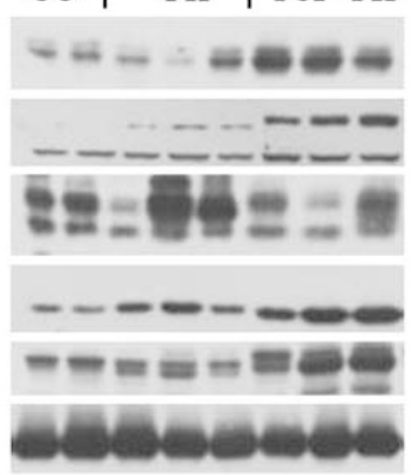

Cyclin D1

p107

p27

PCNA

Cyclin A

Albumin

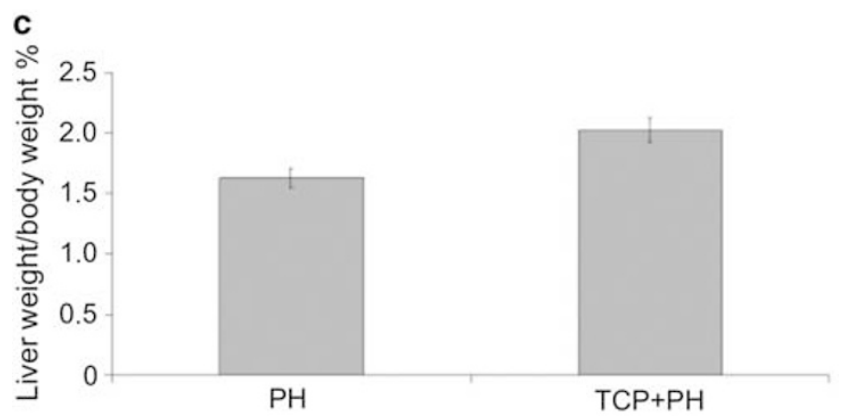

Figure 3 (a) Northern blot analysis of cyclin D1 mRNA levels in the liver from aged mice subjected to $70 \% \mathrm{PH}$, with or without TCPOBOP, and killed $48 \mathrm{~h}$ after $\mathrm{PH}$. Twenty to $30 \mu \mathrm{g} / \mathrm{lane}$ of mRNA were prepared from the liver and northern analysis was performed as described in Materials and Methods. $\beta$-Actin was used as a loading control. TCP, TCPOBOP-treated mice; $\mathrm{CO}$, controls. (b) Western blot analysis of cell-cycle-associated proteins in the liver from aged mice subjected to $70 \% \mathrm{PH}$, with or without TCPOBOP, and killed $48 \mathrm{~h}$ after PH. Nuclear extracts for cyclin D1, p107, p27, PCNA and cyclin A (100-150 $\mu \mathrm{g} / \mathrm{lane})$ were prepared from the livers, and western analysis was performed as described in Materials and Methods. Albumin was used as a loading control. Each lane represents an individual sample. $\mathrm{CO}$, controls. (c) Liver weight/body weight ratio in mice subjected to $\mathrm{PH}$ with or without TCPOBOP pretreatment. Statistically significant for $P<0.05$.

parameters, the $\mathrm{PT}$ and the content of serum albumin, were found to be modified in TCPOBOP-pretreated mice. PT determined $48 \mathrm{~h}$ after $\mathrm{PH}$ was $34 \mathrm{~s} \pm 1.8$ in TCРOBOP-pretreated mice $v s 45 \mathrm{~s} \pm 1.7$ in animals subjected to $\mathrm{PH}$ alone $(P<0.05)$, suggesting a faster recovery in the coagulation capacity of the hyperplastic liver; the PT of untreated mice killed at the same time point was $30.5 \pm 1.3$; determination of albumin serum levels showed higher values in TСРОВОРpretreated mice $(3.79 \pm 0.24 \mathrm{~g} / 100 \mathrm{ml}$ vs $3.11 \pm 0.17 \mathrm{~g} / 100 \mathrm{ml}$; $P<0.05)$ compared with $\mathrm{PH}$ alone. To eliminate the possibility that this albumin was produced by TCPOBOP prior to the time of surgery, we determined the serum albumin content in mice killed 3 days after TCРOBOP, in the absence
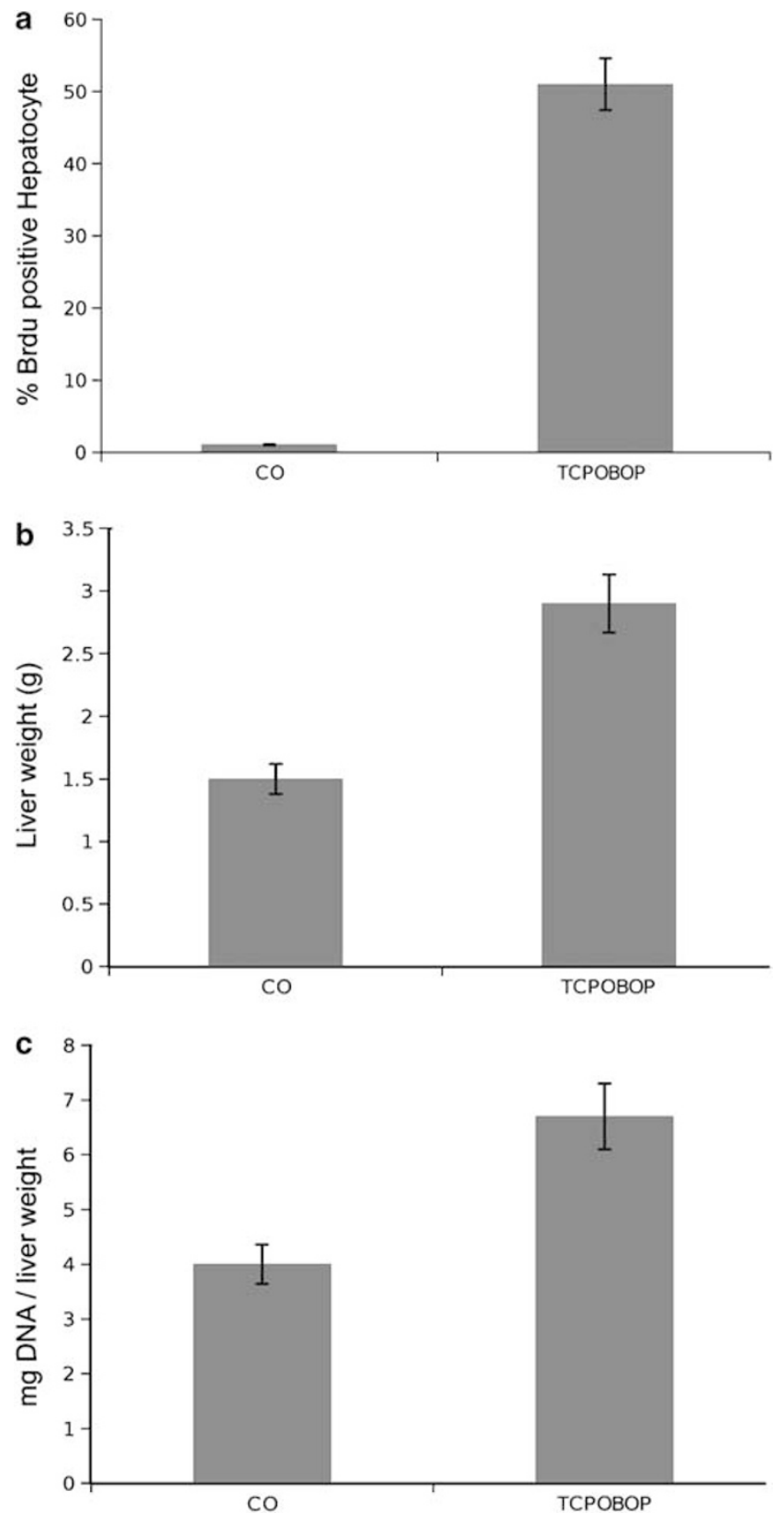

Figure 4 Effect of a single dose of TCPOBOP $(3 \mathrm{mg} / \mathrm{kg}$ ) to intact young mice on $\mathrm{LI}(\mathbf{a})$, liver weight (b) and total liver DNA content (c). Mice were killed 3 days after the administration of TCPOBOP. All mice were given BrdU $(1 \mathrm{mg} / \mathrm{ml})$ in drinking water until the time of killing. Administration of TCPOBOP resulted in an increased LI, larger liver mass and corresponding increase in total hepatic DNA content when compared with controls. Results are expressed as means \pm s.e. of five mice per group. $P<0.001$.

of $\mathrm{PH}$. The results show no change in albumin content $72 \mathrm{~h}$ after ТСРОВОР $(4.14 \pm 0.25 \mathrm{~g} / 100 \mathrm{ml})$ compared with untreated mice $(4.25 \pm 0.14 \mathrm{~g} / 100 \mathrm{ml})$.

\section{DISCUSSION}

Several studies have shown that regeneration following two-third $\mathrm{PH}$ is reduced and delayed in aged rodents. ${ }^{7-10}$ 
Table 1 The effect of ТСРОВОР-induced liver enlargement on the regenerative response after $70 \% \mathrm{PH}$ in young mice

\begin{tabular}{lccccrr}
\hline Treatment & LI (\%) & LW & LW/BW (\%) & $\begin{array}{c}\text { DNA content } \\
\text { mg/g liver }\end{array}$ & mg DNA/LW & mg DNA/\% LW \\
\hline CO & & & & & & \\
PH & $0.91 \pm 0.3$ & $1.54 \pm 0.08$ & $5.24 \pm 0.24$ & $2.55 \pm 0.14$ & $3.91 \pm 0.18$ & $13.31 \pm 0.66$ \\
TCPOBOP+PH & $74.1 \pm 9.5$ & $1.00 \pm 0.06$ & $3.43 \pm 0.13$ & $2.47 \pm 0.05$ & $2.42 \pm 0.20$ & $4.45 \pm 0.48$ \\
\hline
\end{tabular}

Values are expressed as means \pm s.e. of five animals per group.

${ }^{\mathrm{a}}$ Significantly different from $\mathrm{PH}$ for $P<0.001$.
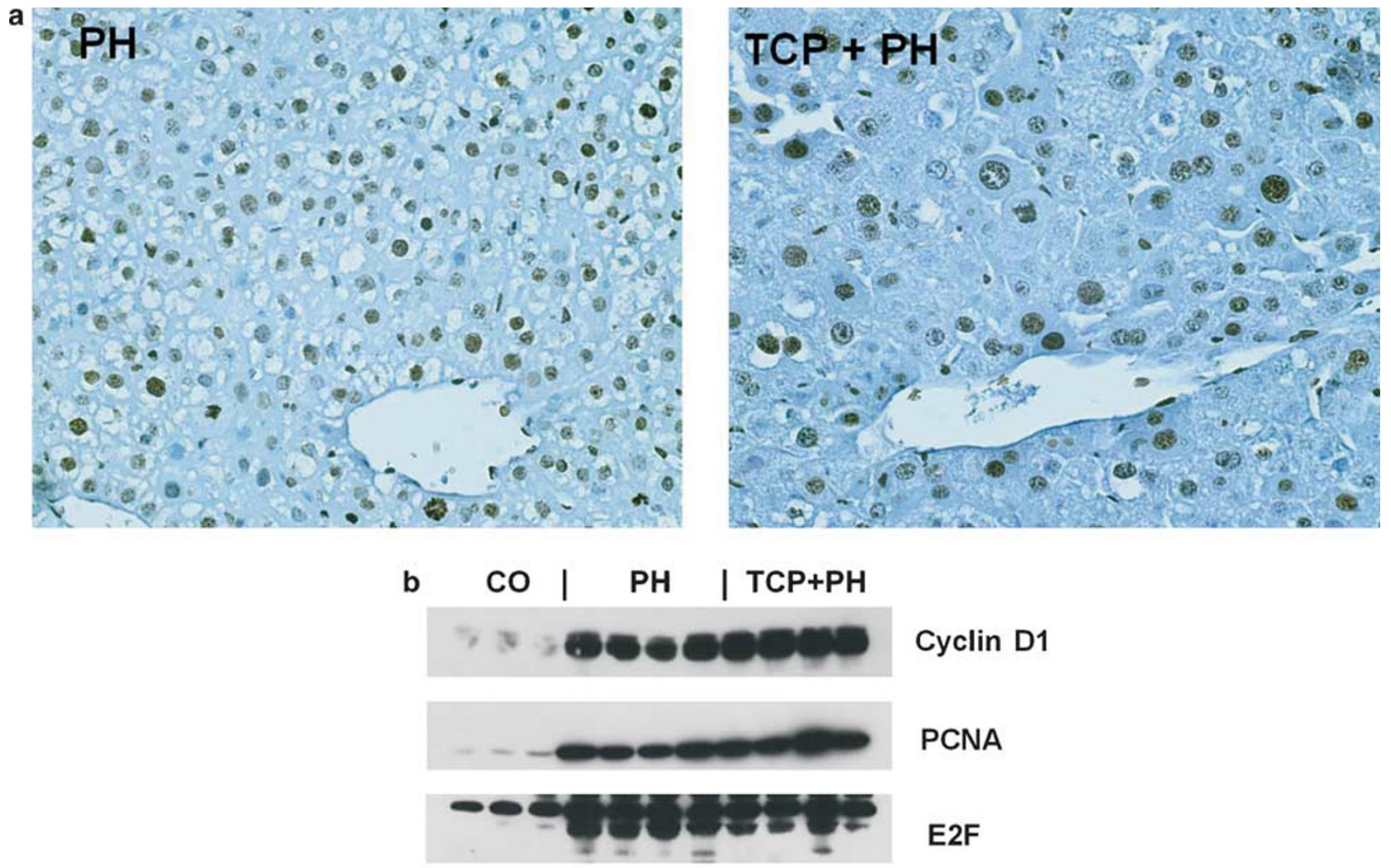

PCNA

E2F

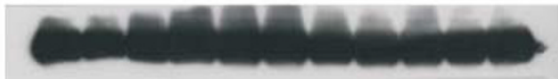

Albumin

Figure 5 (a) Representative photomicrographs, which illustrate the effect of TCPOBOP-induced liver enlargement on the regenerative response, subsequent to two-third $\mathrm{PH}$, in young mice. TCPOBOP $(3 \mathrm{mg} / \mathrm{kg})$ was given 3 days before $\mathrm{PH}$. At this time point, mice were subjected to $70 \% \mathrm{PH}$ and killed $72 \mathrm{~h}$ later. A group of mice was subjected to $\mathrm{PH}$ in the absence of TCPOBOP pretreatment. All animals were given BrdU $(1 \mathrm{mg} / \mathrm{ml})$ in drinking water until the time of killing ( $\times 200$, sections counterstained with hematoxylin). TCP, TCPOBOP-treated mice; (b) western blot analysis of cell cycle-associated proteins. Extracts for cyclin D1, PCNA and E2F (100-150 mg/lane) were prepared from the livers, and western analysis was performed as described in Materials and Methods. Albumin was used as a loading control. Each lane represents an individual sample. TCP, TCPOBOP-treated mice; $\mathrm{CO}$, controls.

However, our previous findings ${ }^{19}$ have shown that the CAR ligand, TCPOBOP, induces hepatocyte DNA synthesis and mitosis in aged mice to the same levels found in young mice, suggesting that the capacity of the hepatocytes to enter cell cycle is maintained during aging, if an appropriate proliferative stimulus is provided. As the signal transduction pathways responsible for the transition from G0 to G1 phase of the hepatocytes in mitogen-induced direct hyperplasia are different from those classically associated to liver regeneration, ${ }^{13}$ the results stemming from the above studies could have significant clinical relevance, as they suggest a potential therapeutic approach to relieve the proliferative block after liver injury that is observed in the elderly. Treatment with mitogens could also have applications in liver transplantation, gene therapy and hepatic failure. 
Here, we showed that although no liver regeneration occurred in aged mice in the first $48 \mathrm{~h}$ after two-third $\mathrm{PH}$, pretreatment with the hepatomitogen ТСРОВОР was able to elicit a conspicuous hepatocyte proliferation associated with an enhanced expression of cell-cycle-related proteins and an increased liver mass. These results, together with our previous findings, ${ }^{19}$ suggest that mitogens may represent a useful tool to stimulate a rapid liver growth when the latter is impaired, such as, for example, when surgical resection is needed in aged patients.

The results of this study are also potentially important in the field of transplantation. Indeed, we showed that a single treatment with ТСРОВОР induces a doubling of the liver mass and, more importantly, of the hepatic DNA content within 3 days. When $70 \% \mathrm{PH}$ was performed in these large livers, a massive liver regeneration (LI was approximately $70 \%$ ) occurred that was similar to that observed in mice subjected to $\mathrm{PH}$ alone. These results clearly suggest that the regenerative capacity after $70 \% \mathrm{PH}$ is independent of the liver size at the time of surgery. This, in turn, suggests that, on a theoretical basis, a drug capable of inducing the same hyperplastic effect in human liver as that was observed in mice could be extremely useful in the field of living-related transplantation for the following reasons: (i) the donor will have a larger liver after partial resection and (ii) the recipient will be transplanted with a larger portion of the liver possessing a full regenerative capacity. It is also important to note that regeneration of a larger liver is associated with improved liver function, as shown by the analysis of the two parameters of liver function, PT and albumin plasma levels, commonly used after hepatic surgery.

A previous study ${ }^{21}$ focused on the potential utility of primary mitogens, within the clinical context of donor conditioning prior to living-related transplantation, was performed with T3, a ligand of the thyroid hormone receptor, which, similar to CAR, is a member of the steroid/thyroid hormone nuclear receptor superfamily. The above study showed that, when the liver mass was increased by an injection of T3, given 10 days previously, and when $70 \% \mathrm{PH}$ performed, there was a larger remnant liver mass and an increased total hepatic DNA content, as compared with rats subjected to PH in the absence of T3 treatment. The results of that study by Malik et $a l^{21}$ in rats are very similar to our present findings in mice. The fact that an increased liver mass could be obtained in two different species (rat and mouse) using two different ligands of nuclear receptors encourages the concept that the strategy of using primary mitogens could be developed to provide better outcomes from surgery. Whether interspecies differences (rodents $v s$ humans) will prevent application of this approach in man will require further experimentation. However, it is important to stress that techniques that could enhance liver mass might extend the possibility of surgery to a greater proportion of patients ${ }^{27}$ and that the use of primary mitogens may form part of such strategies. To accomplish these clinical goals, it will be necessary to extend the observations to other species and to find therapeutic ligands that activate human nuclear receptors such as human CAR.

\section{ACKNOWLEDGEMENT}

Supported by Ministero Università e Ricerca Scientifica (PRIN and ex-60\%), Associazione Italiana Ricerca sul Cancro and Fondazione Banco di Sardegna, Italy.

1. Keswani RN, Ahmed A, Keeffe EB. Older age and liver transplantation: a review. Liver Transpl 2004;10:957-967.

2. Smucker DL. Age-related changes in liver structure and function: implications for disease? Exp Gerontol 2005;40: 650-659.

3. Emre S, Schwartz ME, Altaca G, et al. Safe use of hepatic allografts from donors older than 70 years. Transplantation 1996;62:62-65.

4. Fortner JG, Lincer RM. Hepatic resection in the elderly. Ann Surg 1990;211:141-145.

5. Petrowsky $\mathrm{H}$, Clavien PA. Should we deny surgery for malignant hepato-pancreatic-biliary tumors to elderly patients? World J Surg 2005;29:1093-1100.

6. Ploeg RJ, D'Alessandro AM, Knechtle SJ, et al. Risk factors for primary dysfunction after liver transplantation-a multivariate analysis. Transplantation 1993;55:807-813.

7. Bucher NLR, Swaffield MN, Di Troia JF. The influence of age upon the incorporation of thymidine-2-C14 into the DNA of regenerating rat liver. Cancer Res 1964;24:509-512.

8. Fry MF, Silber J, Loeb LA, et al. Delayed and reduced cell replication and diminishing levels of DNA polymerases- $\alpha$ in regenerating liver of aging mice. J Cell Physiol 1984;118:225-232.

9. lakova $\mathrm{P}$, Awad SS, Timchenko NA. Aging reduces proliferative capacities of liver by switching pathways of CEBP/alpha growth arrest. Cell 2003;113:495-506.

10. Wang X, Quail E, Hung N-J, et al. Increased levels of forkhead box M1B transcription factor in transgenic mouse hepatocytes prevent age-related proliferation defects in regenerating liver. Proc Natl Acad Sci USA 2001;98:11468-11473.

11. Columbano $A$, Shinozuka $H$. Liver regeneration versus direct hyperplasia. FASEB J 1996;10:1118-1128.

12. Moore DD, Kato S, Xie W, et al. International Union of Pharmacology. LXII. The NR1H and NR1I receptors: constitutive androstane receptor, pregnene $X$ receptor, farnesoid $X$ receptor alpha, farnesoid $X$ receptor beta, liver $X$ receptor alpha, liver $X$ receptor beta, and vitamin $D$ receptor. Pharmacol Rev 2006;58:742-759.

13. Ledda-Columbano GM, Columbano A. Mitogenesis by ligands of nuclear receptors: an attractive model for the study of the molecular mechanisms implicated in liver growth. Cell Death Differ 2003;10(Suppl 1):S19-S21.

14. Michalopoulos GK, DeFrances MC. Liver regeneration. Science 1997;276:60-66.

15. Yamada Y, Kirillova I, Peschon JJ, et al. Initiation of liver growth by tumor necrosis factor: deficient liver regeneration in mice lacking type I tumor necrosis factor receptor. Proc Natl Acad Sci USA 1997;94: 1441-1446.

16. Michalopoulos GK. Liver regeneration. J Cell Physiol 2007;213: 286-300.

17. Pibiri M, Ledda-Columbano GM, Cossu C, et al. Cyclin D1 is an early target in hepatocyte proliferation induced by thyroid hormone (T3). FASEB J 2001;15:1006-1013.

18. Ledda-Columbano GM, Curto M, Piga $R$, et al. In vivo hepatocyte proliferation is inducible through a TNF and IL-6-independent pathway. Oncogene 1998;17:1039-1044.

19. Ledda-Columbano GM, Pibiri M, Cossu C, et al. Aging does not reduce the hepatocyte proliferative response of mice to the primary mitogen TCPOBOP. Hepatology 2004;40:981-988.

20. Ben-Haim M, Emre S, Fishbein TM, et al. Critical graft size in adult-to-adult living donor liver transplantation; impact of the recipient's disease. Liver Transpl 2001;7:948-953.

21. Malik R, Habib M, Tootle $R$, et al. Exogenous thyroid hormone induces liver enlargement whilst maintaining regenerative potential. 
A study relevant to donor preconditioning. Am J Transplant 2005;5:1801-1807.

22. Higgins GM, Anderson RM. Experimental pathology of the liver I. Restoration of the liver of the white rat following partial surgical removal. Arch Pathol 1931;12:186-202.

23. Burton K. A study of the conditions and mechanism of the diphenylamine reaction for the colorimetric estimation of deoxyribonucleic acid. Biochem J 1956;62:315-323.

24. Bradford M. A rapid and sensitive method for the quantitation of microgram quantities of protein using the principle of protein-dye binding. Anal Biochem 1976;72:248-254.
25. Columbano A, Ledda-Columbano GM, Pibiri M, et al. GADD45beta is induced through a CAR-dependent TNF-independent pathway in murine liver hyperplasia. Hepatology 2005;42:1118-1126.

26. Calbó J, Parreno M, Sotillo E, et al. G1 cyclin/cyclin-dependent kinasecoordinated phosphorylation of endogenous pocket proteins differentially regulates their interactions with E2F4 and E2F1 and gene expression. J Biol Chem 2002;52:50263-50274.

27. Radaelli CA, Wagner M, Krahenbuhl L, et al. Liver surgery in the era of tissue-preserving resections: early and late outcome in patients with primary and secondary hepatic tumors. World J Surg 2002;26:1126-1132. 